\title{
3D-ITIES supported on porous reticulated vitreous carbon
}

\author{
Shuxin Tan, Mohamad Hojeij, Bin Su, Guillaume Meriguet, \\ Nicolas Eugster, Hubert H. Girault *
}

Laboratoire d'Electrochimie Physique et Analytique, Ecole Polytechnique Fédérale de Lausanne, Station 6, CH-1015 Lausanne, Switzerland

Received 23 June 2006; received in revised form 16 November 2006; accepted 21 November 2006

Available online 1 May 2007

\begin{abstract}
A thin aqueous film prepared by layer-by-layer assembly of oppositely charged polypeptides on 4-aminobenzoic acid modified porous reticulated vitreous carbon (RVC) electrodes was used with the aim of forming a 3D-ITIES. The film containing a redox mediator, namely ferri/ferrocyanide, was placed in contact with an organic solution 1,2-dichloroethane containing an electron acceptor, $7,7^{\prime}, 8,8^{\prime}$-tetracyanoquinodimethane (TCNQ). The reduction of TCNQ was studied to characterise the electrochemical properties of the supported ITIES. When the film is dye-sensitised, a reduction photocurrent was observed upon illumination. This photocurrent was an order of magnitude larger than that measured on a planar electrode.
\end{abstract}

(c) 2006 Elsevier B.V. All rights reserved.

Keywords: Reticulated vitreous carbon; Polypeptide multilayers; Dye-sensitisation; Photocurrent; ITIES

\section{Introduction}

As a clean and permanent energy source, solar energy conversion undoubtedly has attracted much interest. Many approaches rely in mimicking the natural photosynthetic process [1-4], in which photo-induced charge transfer occurs rather efficiently. For example, solar cells based on dye-sensitised nanocrystalline semiconductor films have been extensively studied [4-6]. The major advantage of this approach is the extremely large active surface area resulting in a high photon capture, whilst the major drawback remains the significant energy loss by capture of photoinduced electrons by species in solution (supersensitiser, oxygen, etc.) [6].

More recently, an approach based on dye-sensitised liquid|liquid interfaces between two immiscible electrolyte solutions (ITIES) has been investigated [7-10]. A characteristic feature of this purely molecular approach is that electron exchange involves redox centres separated by a defect-free junction, thereby the separation efficiency of

\footnotetext{
* Corresponding author. Tel.: +41 21693 3151; fax: +41 216933667.

E-mail address: hubert.girault@epfl.ch (H.H. Girault).
}

photoproducts can be improved by reducing the probability of back electron transfer processes due to the differences in solvation energy. The major challenge with this system is the difficulty in generating interfaces with large specific areas so as to enhance the light harvesting. To circumvent this difficulty, we propose here to support ultra-thin aqueous polypeptide multilayer on a porous solid substrate. It is well established that a polypeptide multilayer can be assembled by electrostatic self-assembly on a charged solid substrate [11-13]. For example, positively charged poly-Llysine (pLys) and negatively charged poly-L-glutamic acid (pGlu) can be alternatively deposited on a negative thiolcarboxylate capped gold electrode to form an hydrophilic multilayer [14,15]. When this aqueous film contacts an immiscible organic solution, a polarised ITIES is formed. The major advantage of these supported ITIESs is that they can be studied with a classical three-electrode setup by opposition to conventional freestanding ITIESs that require the use of a four-electrode potentiostat.

Here, a piece of chemically modified reticulated vitreous carbon (RVC) foam serves as a solid substrate to form a 3D-ITIES with a large specific surface area. The difference between an emulsion and a 3D-ITIES is that both phases in 
the 3D-ITIES, i.e. the aqueous phase and the organic phase, form each a unique continuous phase that can be electrochemically controlled. The RVC foam used in this study is a vitreous (amorphous) carbon with properties of high porosity, high strength and rigidity, good electrical conductivity and chemical inertness [16]. To deposit a polypeptide multilayer on the surface of the RVC foam by electrostatic interaction, the RVC foam has first to be modified by 4 -aminobenzoic acid. The polypeptide multilayer selfassembled on the modified RVC surface was then studied for their redox properties. The films were further dye-sensitised, and their photoelectrochemical responses in a hydrophobic organic solution were investigated.

\section{Experimental}

\subsection{Chemicals}

All chemicals were of analytical grade and used as received unless otherwise described. RVC foam (pores $/ \mathrm{cm}$ : 24, porosity: $96.5 \%$, specific surface area: $3.78 \mathrm{~mm}^{2} \mathrm{~mm}^{-3}$, bulk density: $0.05 \mathrm{~g} \mathrm{~cm}^{-3}$, size: $150 \mathrm{~mm} \times 150 \mathrm{~mm} \times 2.5 \mathrm{~mm}$ ) was purchased from Goodfellow Cambridge Limited. The carbon foam sheets were cut into small pieces $(1.0 \mathrm{~cm} \times$ $1.0 \mathrm{~cm} \times 0.25 \mathrm{~cm})$ to be used as electrodes. Poly-L-lysine (pLys, $\left.M_{\mathrm{w}}=30000\right)$ and poly-L-glutamic acid (pGlu, $M_{\mathrm{w}}=$ $50000)$ were obtained from Sigma. Zinc meso-tetrakis( $p$ sulfonatophenyl) porphyrin tetrasodium $\left(\mathrm{Na}_{4} \mathrm{ZnTPPS}\right)$ was bought from Porphyrin Products Inc. 7,7',8,8'-Tetracyanoquinodimethane (TCNQ) is a product of Aldrich. The organic supporting electrolyte, bis(triphenylphosphoranylidene) ammonium tetrakis(pentafluorophenyl)borate (BTPPATPFB), was prepared by metathesis of bis(triphenylphosphoranylidene) ammonium chloride (BTPPACl) and lithium tetrakis(pentafluorophenyl)borate diethyl etherate (LiTPFB) as previously reported [17]. 4-Aminobenzoic acid (4-ABA) and the buffer solution of $\mathrm{pH} 7.0(\sim 0.029 \mathrm{M}$ sodium hydroxide solution and $\sim 0.05 \mathrm{M}$ potassium dihydrogen phosphate) were purchased from Fluka. The buffer solutions of $\mathrm{pH} 8.0$ and $\mathrm{pH} 5.6$ were prepared with $0.1 \mathrm{M}$ potassium dihydrogen phosphate and disodium hydrogen phosphate. The buffer solution of $\mathrm{pH} 2.5$ was prepared from $0.1 \mathrm{M} \mathrm{HCl}$ and $0.1 \mathrm{M} \mathrm{NaOH}$.

\subsection{Electrochemical modification of $R V C$ surface with 4-ABA}

The open cell structure of a reticulated vitreous carbon electrode is illustrated in Fig. 1. The RVC surface was modified with 4-ABA through carbon-nitrogen covalent bonding with the carbon surface, a protocol pioneered by Barbier et al. [18]. Briefly, the modification was conducted in an anhydrous ethanol solution containing $3 \mathrm{mM}$ 4-ABA and $0.1 \mathrm{M} \mathrm{LiClO}_{4}$ by doing cyclic voltammetry for 10 cycles, where the RVC foam functions as the working electrode, a platinum wire as the auxiliary electrode and a silver wire as the quasi-reference electrode (AgQRE). The

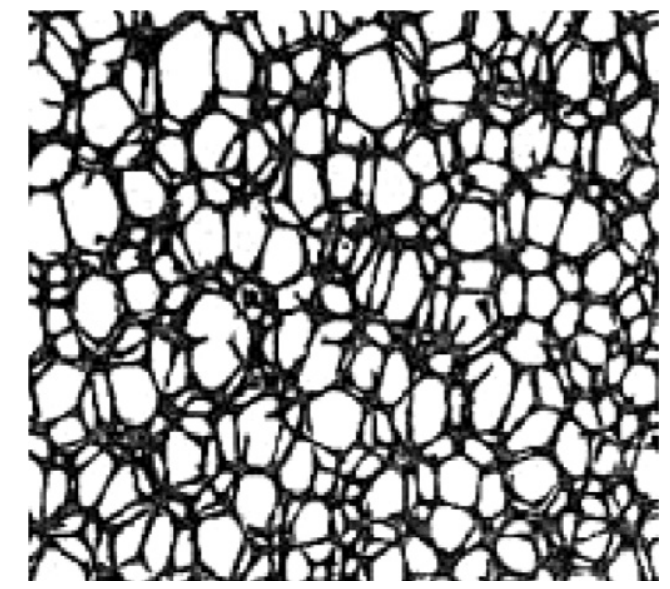

Fig. 1. Schematic illustration of a reticulated vitrous carbon electrode with open cell structure (adapted from http://www.ergaerospace.com).

potential was continuously cycled between $0.1 \mathrm{~V}$ and $1.4 \mathrm{~V}$ (versus AgQRE) at a sweep rate of $0.01 \mathrm{~V} \mathrm{~s}^{-1}$. The modification mechanism is illustrated in Fig. 2a. 4-ABA is oxidised to its amine cation radical, which subsequently binds with the RVC surface to form a very stable carbonnitrogen linkage. After the modification, the RVC electrode was further rinsed with ethanol and Millipore water and sonicated in water for $10 \mathrm{~min}$ to remove the physically adsorbed materials.

\subsection{Fabrication of polypeptide multilayers on $4-A B A$ modified $R V C$ foam}

The polypeptide multilayer was deposited on 4-ABA modified RVC foam as previously reported [19]. Briefly, 4-ABA modified RVC foam was alternatively dipped into pLys $\left(1.0 \mathrm{~g} \mathrm{~L}^{-1}\right)$ and pGlu $\left(1.0 \mathrm{~g} \mathrm{~L}^{-1}\right)$ buffered solutions $(0.1 \mathrm{M}$ phosphate buffer at $\mathrm{pH} 8.0)$ for $30 \mathrm{~min}$ to form a polypeptide multilayer until the desired film was obtained, starting and ending with a pLys layer. Vigorous shaking of the electrodes was carried out when dipping to remove any entrapped bubbles. Between each dipping, the multilayer film was rinsed with Millipore water and dried under nitrogen stream. Subsequently, the multilayer film was immersed in $0.1 \mathrm{M}$ phosphate buffer solution ( $\mathrm{pH}$ 5.6) containing $1.0 \mathrm{mM} \mathrm{K}_{3} \mathrm{Fe}(\mathrm{CN})_{6}$ and $1.0 \mathrm{mM} \mathrm{K}_{4} \mathrm{Fe}(\mathrm{CN})_{6}$ for $20 \mathrm{~min}$ to incorporate ferri/ferrocyanide ions into the film. The $\mathrm{ZnTPPS}^{4-}$ sensitisation was carried out by dipping the as-prepared multilayer film into $1.0 \mathrm{mM} \mathrm{Na} \mathrm{NanTPPS}_{4}$ aqueous solution for $1 \mathrm{~h}$, followed by washing with water and drying under a nitrogen stream. The structure of the dye-sensitised multilayer on the 4-ABA modified RVC foam is schematically depicted in Fig. 2b.

\subsection{Electrochemical measurements}

Cyclic voltammetry was performed on a CHI 900 electrochemical workstation ( $\mathrm{CH}$ Instrument, USA) in a conventional three-electrode configuration. The RVC foam 

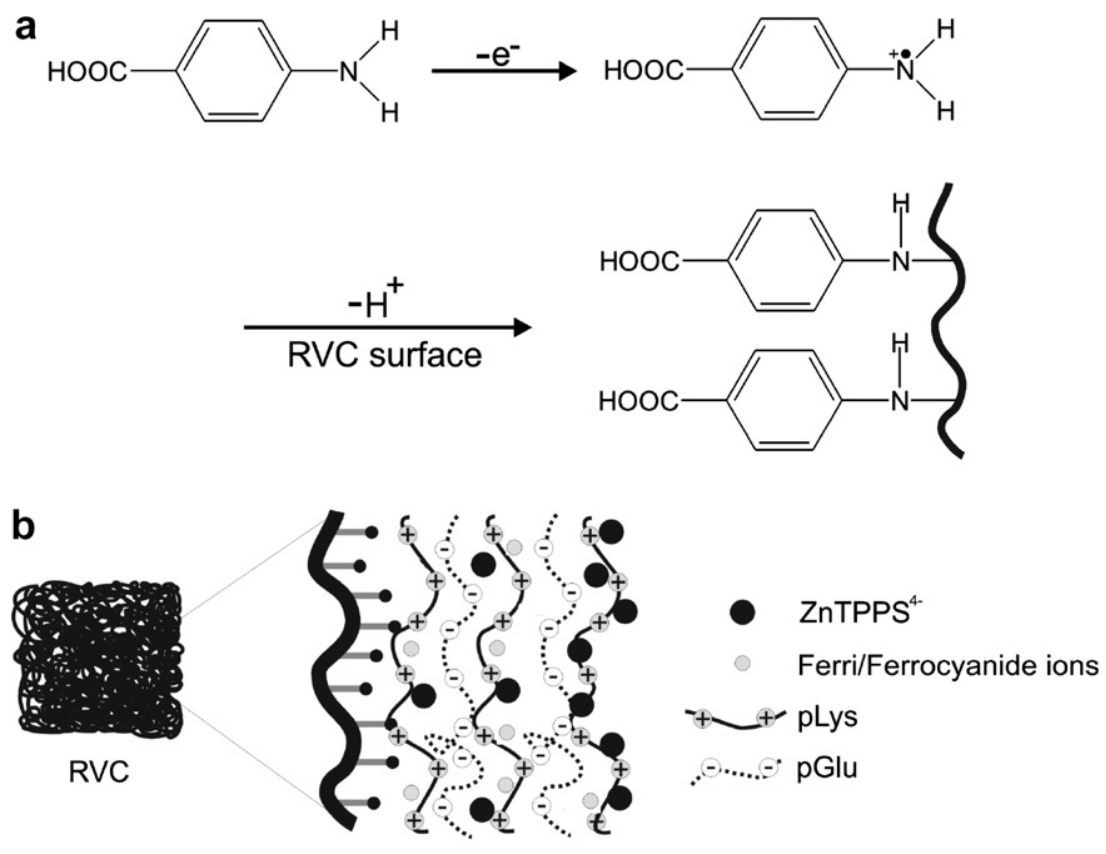

RVC $\mid$ ABA $:$ pLys, pGlu...ZnTPPS

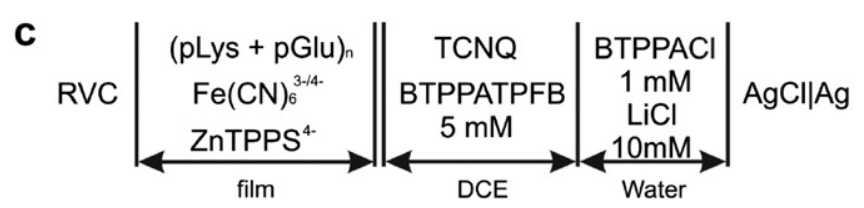

Fig. 2. (a) The chemical process of modifying RVC surface with 4-ABA; (b) schematic illustration of the structure of a dye-sensitized polypeptide multilayer on the 4-ABA modified RVC foam; (c) schematic composition of the electrochemical cell for measurements in DCE.

or the modified RVC foam was used as a working electrode and a platinum wire as the auxiliary electrode. $\mathrm{An} \mathrm{Ag} \mid \mathrm{AgCl}$ wire was used as the reference electrode for the measurements in aqueous media. In the case of cyclic voltammetry in 1,2-dichloroethane (DCE) solution, $5 \mathrm{mM}$ BTPPATPFB was used as the supporting electrolyte and an $\mathrm{Ag} \mid \mathrm{AgCl}$ wire functions as the reference electrode together with a nonpolarisable water|DCE interface. The corresponding cell composition is schematically illustrated in Fig. 2c.

\subsection{UV-vis absorption measurements}

Sensitisation of the polypeptide multilayer by ZnTPPS ${ }^{4-}$ was checked by UV-vis absorption measurements, which were performed on an Ocean Optics CHEM2000-UV-vis spectrometer. To carry out these measurements in the transmission mode, the dye-sensitised multilayer was deposited on negatively charged glass slides treated with a Piranha solution (a 4:1 mixture of concentrated sulfuric acid and hydrogen peroxide $\left(30 \% \mathrm{H}_{2} \mathrm{O}_{2}\right.$ in water $)$ ).

\subsection{Photocurrent measurements}

Photocurrent transient measurements were performed under potentiostatic conditions and the electrochemical cell was open to the air, where the external potential was supplied by a Hi-Tek waveform generator (Hi-Tek Instruments PP-R1). The illumination was carried out with a beam line of $454 \mathrm{~nm}$ from an argon ion tunable laser (Omnichrome series 43) with a photon flux of $6 \times 10^{16}$ $\mathrm{cm}^{-2} \mathrm{~s}^{-1}$. The photon flux was quantitatively determined by a calibrated power meter (Gentec, TPM-310). An optical shutter with an aperture time in the range of microseconds was used to control the illumination time.

\section{Results and discussion}

\subsection{4-ABA modified $R V C$ foam}

The modification of the RVC surface to a charged state is crucial for the build-up of the polypeptide multilayer. According to a previously reported protocol [18], the RVC surface was first modified with a carboxyl-terminated 4-ABA monolayer as illustrated in Fig. 2a. The deprotonation of carboxylic groups makes the RVC surface negatively charged [20]. The modification of the RVC surface with 4-ABA is confirmed by cyclic voltammetry as illustrated in Fig. 3. At $\mathrm{pH} 7.0$, the response for a $5 \mathrm{mM}$ $\mathrm{K}_{3} \mathrm{Fe}(\mathrm{CN})_{6}$ aqueous solution on a 4-ABA modified RVC electrode (Fig. 3a, dashed line) features compared to the 
bare carbon foam (Fig. 3a, solid line) a smaller peak current and a larger peak-to-peak separation. This observation can be ascribed to the electrostatic repulsion between $\mathrm{Fe}(\mathrm{CN})_{6}^{3-/ 4-}$ and the $\mathrm{COO}^{-}$terminated $\mathrm{RVC}$ electrode, since at $\mathrm{pH} 7.0$ the tethered carboxylic groups are deprotonated. This repulsive interaction slows down the interfacial kinetics of the electrochemical response of $\mathrm{Fe}(\mathrm{CN})_{6}^{3-/ 4-}$ [21-24]. Decreasing the $\mathrm{pH}$ of the aqueous solution to 2.5, a more quasi-reversible response at the 4-ABA modified RVC foam (Fig. 3a, dotted line) was recovered. At $\mathrm{pH} 2.5$, the carboxyl groups are protonated, thus the electrode surface is uncharged and no longer hinders the approach of $\mathrm{Fe}(\mathrm{CN})_{6}^{3-/ 4-}$ to the electrode surface. The surface property of 4-ABA modified RVC foam was also examined by considering the redox behaviour of neutral ferrocenemethanol $(\mathrm{FcMeOH})$. As displayed in Fig. 3b, at $\mathrm{pH} 7.0$ though the electrode surface is negatively charged, it does not affect the electrochemical response of $\mathrm{FcMeOH}$ on the electrode. The above experimental observations indicate that 4-ABA was successfully deposited on the RVC surface and that it is negatively charged at neutral $\mathrm{pH}$. However, it should be noted that the microscopic structure of 4-ABA layer has not been studied here, the aim being just to verify that a negatively charged RVC surface can be obtained to support the electrostatic assembly of polypeptide ions.
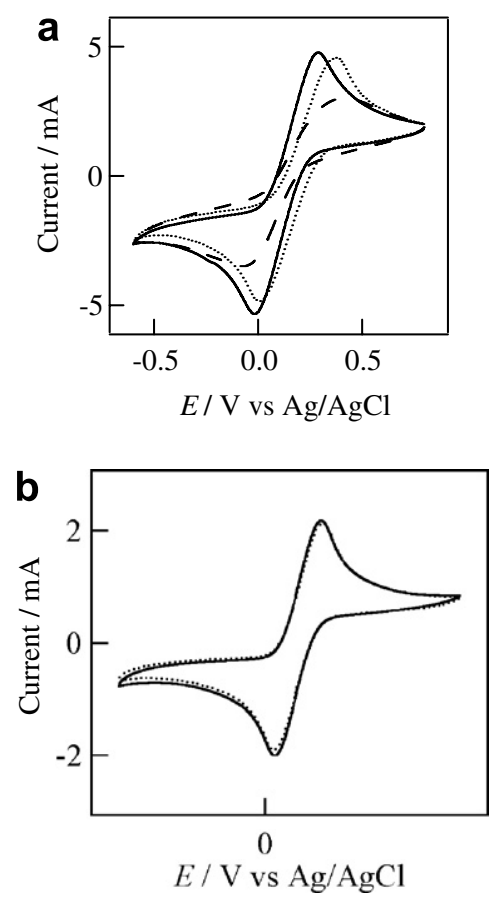

Fig. 3. (a) CVs of a bare (solid line) and a 4-ABA modified RVC electrodes in $5 \mathrm{mM} \mathrm{K}_{3} \mathrm{Fe}(\mathrm{CN})_{6}$ at either $\mathrm{pH} 7.0$ (dashed line) or $\mathrm{pH} 2.5$ (dotted line); (b) CVs of a bare (dotted lines) and a 4-ABA modified (solid line) $\mathrm{RVC}$ electrodes in $2 \mathrm{mM}$ ferrocenemethanol at $\mathrm{pH}$ 7.0. All measurements were performed at a scan rate of $0.05 \mathrm{~V} \mathrm{~s}^{-1}$.

\subsection{Electrochemical properties of $3 D$-ITIES}

Fig. 4 shows cyclic voltammetry responses of the (pLys/ pGlu $)_{3} /$ pLys film in contact with a DCE solution in a potential range of $\pm 1.0 \mathrm{~V}$. The dotted curve in Fig. $4 \mathrm{a}$ corresponds to the polyelectrolyte film modified carbon electrode in the absence of any redox couple. In the potential range between $-0.3 \mathrm{~V}$ and $1.0 \mathrm{~V}$, only a capacitive current is observed. However, at more negative potentials, an irreversible voltammetric response arises, which can be ascribed to oxygen reduction since the experiment was carried out in the air.

In the presence of ferri/ferrocyanide in the film, a voltammetric response as shown by the solid curve in Fig. $4 \mathrm{a}$ is observed with an half-wave potential value around $0.1 \mathrm{~V}$. The peak-to-peak separation is wider than expected for adsorbed redox species on electrode surfaces or even for a thin layer cell. This response is quite similar to that of ferri/ferrocyanide in a polyelectrolyte multilayer assembled on mercaptoundecanoic acid-modified planar gold electrodes for which the mechanism is not yet fully elucidated $[14,15,25,26]$. Of course, the redox reaction of ferri/ferrocyanide inside the film must be accompanied by the ionic transport across the film|DCE interface to main-
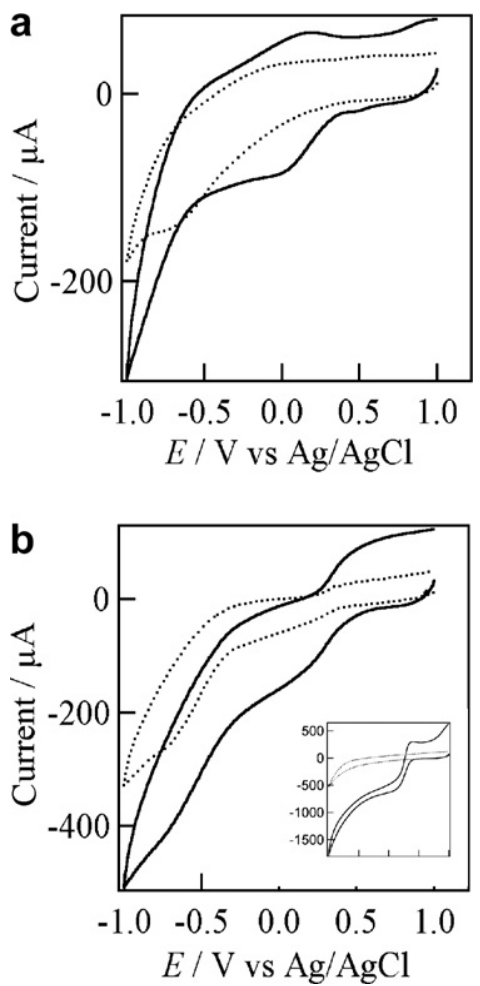

Fig. 4. CVs of polypeptide film ((pLys/pGlu $\left.)_{3} / \mathrm{pLys}\right)$ placed in contact with DCE at a scan rate of $0.1 \mathrm{~V} \mathrm{~s}^{-1}$. (a) In the absence (dotted line) and presence (solid line) of $\mathrm{Fe}(\mathrm{CN})_{6}^{3-} / \mathrm{Fe}(\mathrm{CN})_{6}^{4-}$ in the film. (b) The absence (dotted line) and presence (solid line) of $\mathrm{Fe}(\mathrm{CN})_{6}^{3-} / \mathrm{Fe}(\mathrm{CN})_{6}^{4-}$ in the film in DCE solution containing $2 \mathrm{mM}$ TCNQ. The insert in (b) shows the CVs of bare carbon foam in DCE solution in the absence (dotted line) and presence (solid line) of TCNQ. 
tain the electroneutrality of the film. The large peak-topeak potential separation observed reflects the sluggish kinetics of the surface reaction (as shown in Fig. 3a), further impeded by the electrostatic and/or steric barrier exerted by the highly charged polyelectrolyte layers, as discussed previously $[14,25]$. In any case, these data indicates that ferri/ferrocyanide ions are incorporated into the RVC supported multilayer and can play the role of redox mediators. The electron transport inside the film through ferri/ ferrocyanide ions is believed to proceed mostly via electron hopping from redox site to redox site, rather than by diffusion of ferri/ferrocyanide ions $[25,27]$.

When a simple polyelectrolyte coated carbon electrode (in the absence of ferri/ferrocyanide) is placed in an organic electrolyte as shown in Fig. 2c containing the electron acceptor TCNQ, we can observe in Fig. $4 \mathrm{~b}$ that compared to a bare carbon electrode (Fig. $4 \mathrm{~b}$, insert) the reduction current of TCNQ is suppressed. Only a very small residual current can be detected. This clearly shows that the thin aqueous film forms a strong hydrophilic barrier preventing hydrophobic species from accessing the electrode. The small residual reduction current may stem from pinholes in the film and/or from a partial distribution of neutral TCNQ in the aqueous layer. When the aqueous film is doped with ferri/ferrocyanide, a catalytic current can be observed as shown by the solid curve in Fig. $4 \mathrm{~b}$. In this process, $\mathrm{Fe}(\mathrm{CN})_{6}^{3-/ 4-}$ functions as an aqueous redox relay mediating the electron transport between the carbon foam electrode and TCNQ in DCE. The major difference between a classical modified electrode and a supported ITIES is that, in the latter case, the electron transfer reaction between the mediator and the reacting species occurs at a polarised liquid|liquid interface. Indeed, in most modified electrodes the film|solution interface is not polarised and often the reacting species can partition in the film. These voltammetric data clearly show that the film deposition protocol is suitable for the formation of supported 3DITIES.

\subsection{Photoelectrochemical properties of dye-sensitised 3D-ITIES}

Fig. 5 displays the UV-vis spectrum of porphyrins absorbed on a (pLys/pGlu) 3 /pLys film on a pre-treated glass slide. The characteristic Q and Soret bands of porphyrin are found in the spectrum, which confirms the uptake of negatively charged porphyrin ions on the film. However, these characteristic bands shift to longer wavelengths (ca. $10 \mathrm{~nm}$ ) and are broader compared with the corresponding band in the absorption spectra of the $\mathrm{Na}_{4} \mathrm{ZnTPPS}$ dilute aqueous solution (also shown in Fig. 5). The strong electronic interaction between porphyrin molecules absorbed on the film and an increase in polarity of the polypeptide matrix compared to the aqueous solution are likely to explain this bathochromic shift $[25,28-30]$. The broadness of the absorption spectrum may result from the aggrega-

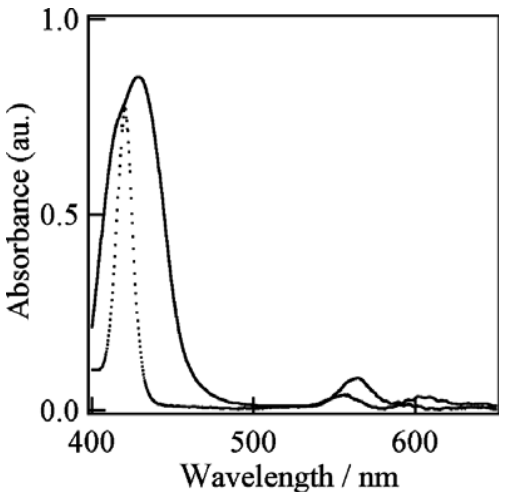

Fig. 5. UV-vis absorption spectra of $\mathrm{ZnTPPS}^{4-}$ sensitised multilayer ((pLys/pGlu) $3 /$ pLys) on glass slide (solid line) and $\mathrm{Na}_{4} \mathrm{ZnTPPS}$ dilute aqueous solution (dotted line).

tion of porphyrin molecules with each other on the polyelectrolyte film [31].

Photocurrent responses were used to characterise the photoelectrochemical properties of the dye-sensitised 3DITIES. Fig. 6 shows different photocurrent transients at $0.0 \mathrm{~V}$ for a $\mathrm{ZnTPPS}^{4-}$ sensitised ((pLys/pGlu) $\left.{ }_{3} / \mathrm{pLys}\right)$ film on a 4-ABA modified RVC foam electrode in contact with a DCE solution. In the absence of redox mediators in the film, only a small photocurrent can be observed (Fig. 6, dotted line) when an electron acceptor is present in the organic phase, the recycling of the oxidised dye being then a slow process. When the film contains $\mathrm{Fe}(\mathrm{CN})_{6}^{3-/ 4-}$, the photocurrent magnitude is increased by a factor of 3.4 (Fig. 6, solid line) confirming that ferri/ferrocyanide ions function as an electron shuttle, through which the electrons hop from the RVC electrode to the sensitiser ZnTPPS $^{4-}$ as illustrated by the solid arrow in Fig. 7. In this case, the excited aqueous dye is interfacially quenched by TCNQ in the adjacent organic phase, and the resulting oxidised dye is then reduced by $\mathrm{Fe}(\mathrm{CN})_{6}^{4-}$ yielding an overall

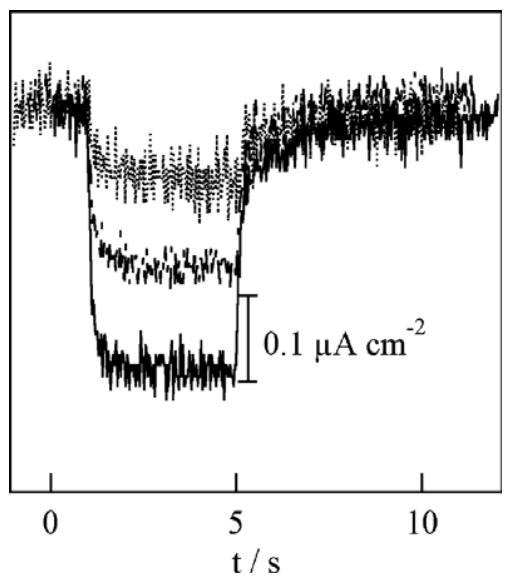

Fig. 6. Photocurrent transients of the ZnTPPS ${ }^{4-}$ sensitised multilayer ((pLys/pGlu $\left.)_{3} / \mathrm{pLys}\right)$ at $0 \mathrm{~V}$ in contact with the DCE solution (illuminated area: $0.49 \mathrm{~cm}^{2}$ ). From top to bottom: $0.1 \mathrm{mM}$ TCNQ in DCE (dot line), $\mathrm{Fe}(\mathrm{CN})_{6}^{3-} / \mathrm{Fe}(\mathrm{CN})_{6}^{4-}$ in the film, no TCNQ (dashed line) and $\mathrm{Fe}(\mathrm{CN})_{6}^{3-} / \mathrm{Fe}(\mathrm{CN})_{6}^{4-}$ in the film and $0.1 \mathrm{mM}$ TCNQ in DCE (solid line). 
photoreduction current. In Fig. 7, the direct dark reduction of TCNQ by $\mathrm{Fe}(\mathrm{CN})_{6}^{4-}$ discussed above is illustrated by the dashed arrows.

For comparison, Fig. 6 also shows the photocurrent transients of ZnTPPS ${ }^{4-}$-sensitised/redox doped film placed in contact with DCE in the absence of TCNQ. A photocurrent can still be observed (Fig. 6, dashed line) though smaller than in the presence of TCNQ. This photocurrent results from the reduction of dissolved oxygen. Indeed, oxygen can be reduced to hydrogen peroxide by sensitised porphyrins. Considering the experimental conditions, oxygen is a component of the system and is involved in the interfacial electron transfer reaction as an electron acceptor. Indeed, there are already a few reports in the literature on the reduction of oxygen at liquid|liquid interfaces [32-35].

The advantage of using porous structured RVC electrodes as substrates is examined by comparing the photoelectrochemical responses of dye-sensitised polypeptide film on porous reticulated vitrous carbon and on a flat glassy carbon electrode. Fig. 8 show the photocurrent transients of both modified electrodes at the applied potential of $0 \mathrm{~V}$. At this potential, the photocurrent and the incident photon-to-electron conversion efficiency (IPCE) is increased by the factor of ca. eight times for the RVC foam $\left(0.34 \mu \mathrm{A} \mathrm{cm} \mathrm{cm}^{-2}, 0.004 \%\right)$ over the flat electrode $(0.04$ $\left.\mu \mathrm{A} \mathrm{cm}^{-2}, 0.0005 \%\right)$. The surface area of $\mathrm{RVC}$ foam is calculated as 9.45 times that of the flat electrode according to the specific surface area of the RVC foam. This means that the photocurrent increases proportionally with the specific surface area. Of course, it would be advantageous if 3D-ITIES could improve the photon adsorption crosssection of the dyes. However, it is clear that black carbon is a very poor scattering material and that almost all the photons that passes through the thin aqueous film are adsorbed by the structure. Perhaps, the use of solid metallic open cell foam may improve the IPCE.

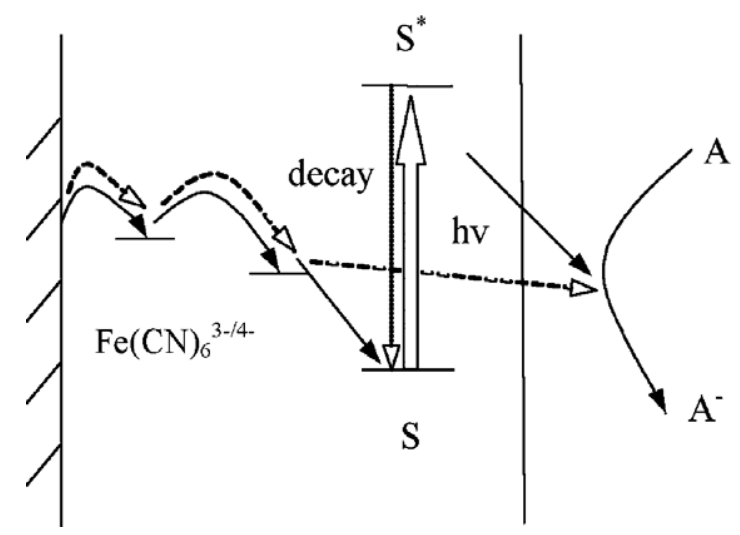

Fig. 7. A schematic diagram to illustrate the electron transfer chain reactions through the film upon photosensitisation (solid arrows) and in the dark (dashed arrows). S, $\mathrm{S}^{*}$ and A denote dye in ground state, dye in excited state and the electron acceptor present in DCE, respectively.

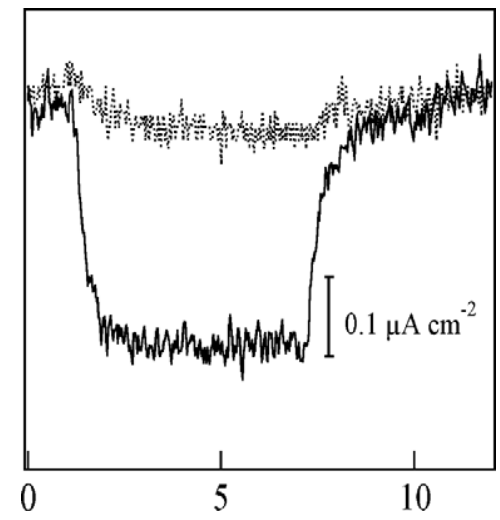

Fig. 8. Photocurrent transients at $0 \mathrm{~V}$ vs. $\mathrm{Ag} / \mathrm{AgCl}$ of $\mathrm{ZnTPPS}^{4-}$-(pLys/ $\mathrm{pGlu})_{3} / \mathrm{pLys}$ on a 4-ABA modified planar disc-glassy-carbon electrode (dotted line) and carbon foam electrode (solid line) both loaded with $\mathrm{Fe}(\mathrm{CN})_{6}^{4-/ 3-}$ in 1,2-DCE solution containing $5 \mathrm{mM} \mathrm{BTPPATPFB}+$ $0.1 \mathrm{mM}$ TCNQ (the illuminated area is $0.2 \mathrm{~cm}^{2}$ ).

\section{Conclusion}

Reticulated vitreous carbon (RVC) foam featuring a large surface area was used as the substrate support for construction of dye-sensitised hydrophilic polypeptide multilayer film after a pre-modification with 4-aminobenzoic acid. The photoelectrochemical responses of the film were investigated in 1,2-dichloroethane. A much larger photocurrent magnitude was obtained in comparison with a flat substrate, indicating the porously structured substrate is more desirable than the flat one for photo-energy conversion systems. This work opens the way for the design of volumic systems to support liquid|liquid interface of large specific surface area. The long-term objective is to obtain very large polarised molecular interface whilst maintaining the continuous electrical contact in the respective phase.

\section{Acknowledgements}

The present work is partly supported by grants from EPFL and the Fonds National Suisse de la Recherche Scientifique (200020-105486). The technical assistance by Valerie Devaud is also acknowledged.

\section{References}

[1] H.T. Tien, Nature 219 (1968) 272.

[2] T.A. Moore, D. Gust, P. Mathis, J.C. Mialocq, C. Chachaty, R.V. Bensasson, E.J. Land, D. Doizi, P.A. Liddell, et al., Nature 307 (1984) 630

[3] D. Gust, T.A. Moore, Science 244 (1989) 35.

[4] B. O'Regan, M. Graetzel, Nature 353 (1991) 737.

[5] M. Gratzel, Nature 414 (2001) 338.

[6] M. Graetzel, Inorg. Chem. 44 (2005) 6841.

[7] D.J. Fermin, Z. Ding, H.D. Duong, P.F. Brevet, H.H. Girault, Chem. Commun. (1998) 1125.

[8] D.J. Fermin, Z. Ding, H.D. Duong, P.-F. Brevet, H.H. Girault, J. Phys. Chem. B 102 (1998) 10334.

[9] D.J. Fermin, H.D. Duong, Z. Ding, P.F. Brevet, H.H. Girault, Electrochem. Commun. 1 (1999) 29. 
[10] D.J. Fermin, H. Dung Duong, Z. Ding, P.F. Brevet, H.H. Girault, Phys. Chem. Chem. Phys. 1 (1999) 1461.

[11] Y. Lvov, G. Decher, H. Moehwald, Langmuir 9 (1993) 481.

[12] G. Decher, J.D. Hong, Makromol. Chem. Macromol. Symp. 46 (1991) 321.

[13] G. Decher, Science 277 (1997) 1232.

[14] Y. Cheng, L. Murtomaki, R.M. Corn, J. Electroanal. Chem. 483 (2000) 88.

[15] Y. Cheng, R.M. Corn, J. Phys. Chem. B 103 (1999) 8726.

[16] R.T. Muehleisen, C.W.I.V. Beamer, B.D. Tinianov, J. Acoust. Soc. Am. 117 (2005) 536.

[17] B. Su, J.-P. Abid, D.J. Fermin, H.H. Girault, H. Hoffmannova, P. Krtil, Z. Samec, J. Am. Chem. Soc. 126 (2004) 915.

[18] B. Barbier, J. Pinson, G. Desarmot, M. Sanchez, J. Electrochem. Soc. 137 (1990) 1757.

[19] J.J. Kakkassery, D.J. Fermin, H.H. Girault, Chem. Commun. (2002) 1240.

[20] J. Liu, L. Cheng, B. Liu, S. Dong, Langmuir 16 (2000) 7471.

[21] V. Pardo-Yissar, E. Katz, O. Lioubashevski, I. Willner, Langmuir 17 (2001) 1110.

[22] C. Saby, B. Ortiz, G.Y. Champagne, D. Belanger, Langmuir 13 (1997) 6805.
[23] J. Madoz, B.A. Kuznetzov, F.J. Medrano, J.L. Garcia, V.M. Fernandez, J. Am. Chem. Soc. 119 (1997) 1043.

[24] Q. Cheng, A. Brajter-Toth, Anal. Chem. 67 (1995) 2767.

[25] J.J. Kakkassery, PhD Thesis, Ecole Polytechnique Fédérale de Lausanne, Lausanne, 2004.

[26] H. Hoffmannova, D. Fermin, P. Krtil, J. Electroanal. Chem. 562 (2004) 261.

[27] M. Hojeij, N. Eugster, B. Su, H.H. Girault, Langmuir 22 (2006) 10652.

[28] K. Ariga, Y. Lvov, T. Kunitake, J. Am. Chem. Soc. 119 (1997) 2224.

[29] R.R. Barto Jr., C.W. Frank, P.V. Bedworth, S. Ermer, R.E. Taylor, J. Phys. Chem. B 108 (2004) 8702.

[30] G.A. Schick, I.C. Schreiman, R.W. Wagner, J.S. Lindsey, D.F. Bocian, J. Am. Chem. Soc. 111 (1989) 1344.

[31] K. Aramata, M. Kamachi, M. Takahashi, A. Yamagishi, Langmuir 13 (1997) 5161.

[32] D.T. Sawyer, Oxygen Chemistry, Oxford University Press, Oxford, 1991.

[33] P. Liljeroth, B.M. Quinn, K. Kontturi, Langmuir 19 (2003) 5121.

[34] V.J. Cunnane, G. Geblewicz, D.J. Schiffrin, Electrochimica Acta 40 (1995) 3005.

[35] H. Ohde, K. Maeda, Y. Yoshida, S. Kihara, J. Electroanal. Chem. $483(2000) 108$. 